\title{
Competitive empathy: sharing values and strategies with rivals
}

\author{
Antonio Ghezzi
}

Strategy and empathy: what about competitors?

Strategy traditionally centers around the notion of competitive advantage and the need to be different from competitors to obtain superior performance. Such an idea is deeply rooted in managers' and entrepreneurs' way of conceiving and executing strategy, leading them to believe that dealing with competitors in a hostile and antagonistic manner is their only viable option, a sort of fundamental requirement for any company searching to survive and thrive in the competitive landscape.

However, in times of unprecedented disruptions coming from all directions - technological, pandemic and cultural - this traditional strategic storytelling must pivot: managers should take a different stance and learn to practice empathy, to see, perceive and feel the world as others do - including competitors.

An organization's survival goes along with the ability to see the world from a shared perspective, to interpret a jigsaw of data and information in a unified and intelligent way and to envision how to orchestrate an ecosystem. Empathy is not simply a cognitive and emotional facet but becomes an essential strategic skill.

The relationship between empathy and strategy was already hinted at by a limited number of studies, which recognized how nurturing empathy could be beneficial to managers, especially when dealing with customers, colleagues and employees and stakeholders.

Empathy directed toward customers helps managers feel what their customers feel and sense what they may need (Goleman et al., 2017). Empathy allows an organization to focus on customer problems or pains to propose a solution. It may disclose new sources of customer gains that may improve satisfaction and delight. Introspection and sincere curiosity are key to improve one's ability to practice empathy when reading customers (Bregman, 2020).

Similarly, empathizing with colleagues and employees, which requires thinking about and understanding how they feel, contributes to the creation of a healthier workplace, characterized by stronger collaboration, reduced stress and conflict and higher morale. By building empathy through crystallizing it into social norms and recruiting "empathic champions" to support those norms, managers can make empathy a vibrant part of the organizational culture (Zaki, 2019). Through empathy, leaders succeed in explaining themselves in more meaningful ways and may increase the performance of their colleagues and direct reports (Goleman et al., 2017).

Empathy may also target a broader range of stakeholders in the company's value network and ecosystems such as suppliers, investors, governments, national and local communities, labor unions and non-government organizations.
Antonio Ghezzi is based at the Department of Management, Economics and Industrial Engineering, Politecnico di Milano, Milan, Italy.

(C) Antonio Ghezzi. Published by Emerald Publishing Limited. This article is published under the Creative Commons Attribution (CC BY 4.0) licence. Anyone may reproduce, distribute, translate and create derivative works of this article (for both commercial and non-commercial purposes), subject to full attribution to the original publication and authors. The full terms of this licence may be seen at http:// creativecommons.org/licences/ by/4.0/legalcode 
Empathizing with stakeholders may help to anticipate their concerns, align incentives and nurture a sense of community. It may stimulate the company's competitive imagination through pooling external and internal stakeholder knowledge, especially when involving isolated stakeholders at the fringe of the company's network (Hart and Sharma, 2004). Empathy toward stakeholders also lies at the core of a shared value approach whose goal is to connect societal and economic progress in a shared value view, setting policies and operating practices that enhance the competitiveness of a company while simultaneously advancing the economic and social conditions in the communities where it operates (Porter and Kramer, 2019).

Although these streams of research hold great potential, our study claims that they consistently leave a key actor out of the equation, that is, competitors. This neglect may affect managers' ability to get the most out of empathy in all of its possible domains of application.

Placing empathy at the core of strategic thinking and behavior gets managers to put themselves in customers' shoes to uncover hidden pain and improve customer experience (Patnaik, 2009). It may inspire employees and team members to embrace the company's mission and work together to pursue a higher purpose (Myashiro and Colonna, 2011; Duarte, 2020) or generate shared value with stakeholders (Hart and Sharma, 2004). It also encourages an unconventional view on competition (Figure 1).

\section{Strategizing with a shared purpose}

The idea of empathy for competitors takes stock of my published academic and practitioner studies on strategic renewal and business model design, validation and innovation applied to both incumbents and startups. I focus on strategic and organizational drivers and business model mechanisms of interdependency and complementarity to foster the formulation, validation and execution of platform strategies and digital transformation (Cortimiglia et al., 2016; Frank et al., 2019; Ghezzi, 2020).

To generate, this research leverages the different methods associated with the streams of academic and professional experience:

- "class as a lab" research, including experimental and action learning approaches to executives, managers and entrepreneurs taking part in post-graduate courses and programs;

- field studies covering strategic innovation endeavors in varied contexts such as eCommerce, food, technology provisioning, insurance, logistics, utilities and space economy; and

- collaborative research within my entrepreneurial experience as startup cofounder.

Figure 1 Empathy at the core of a company's relations with customers, employees, stakeholders and competitors

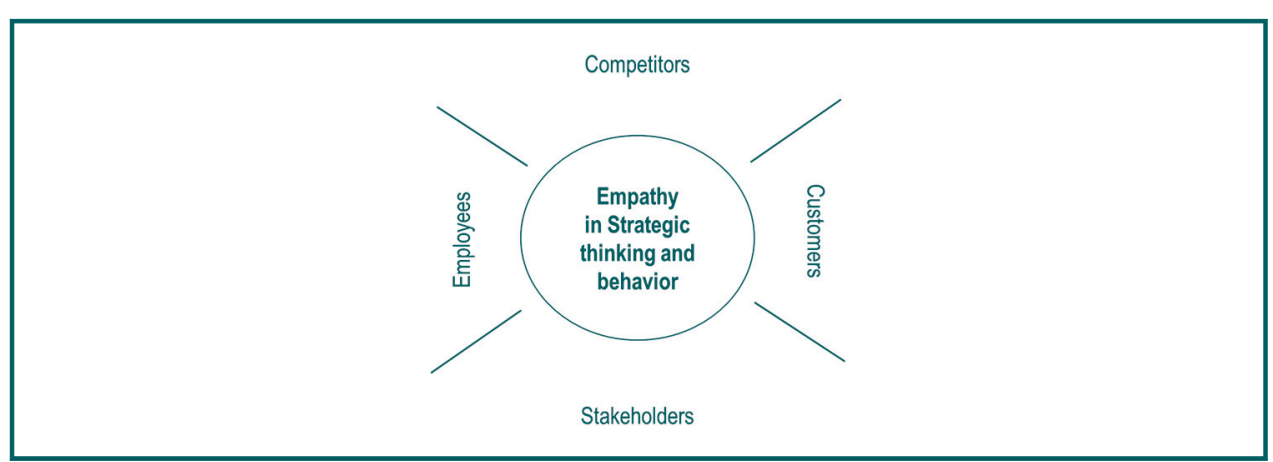


Competitive empathy forces one to go beyond competitive attrition and the related search for competitive differentials and asymmetries to simply throw rivals off balance. On the contrary, it puts similarities, symmetries, complementarities and common views shared with competitors in the spotlight.

Competitive empathy as a notion contributes to the operationalization of the relationship between strategy and purpose (Bartlett and Ghoshal, 1994). It ultimately discusses the reason why a company exists and operates and how it aims to have a positive footprint on the whole world well beyond profitability.

The attempt to put purpose at the core of a company's strategy (Malnight et al., 2019) requires revisiting the common view on competitors to develop a shared purpose with rivals and strive to collectively build a better future for all.

\section{The competitive empathy catalyst}

The effort to be more empathic and emotionally intelligent when dealing with competitors often relies on experimental and action learning approaches such as self-assessments, case discussions, videos analysis and interpretation, role-taking and serious games interactions. I designed the "Competitive Empathy Catalyst" tool, which identifies three layers, orientation, execution and foundation to find common ground between the company's and its competitors' strategy (Table 1).

The Orientation layer refers to the way a company and its competitors are similar in how they see the world and their long-term role in it, aim for a higher purpose or reason and set strategic goals. This layer is made of three building blocks, each accompanied by a list of questions managers should ask themselves to facilitate the adoption of an empathic stance toward competition:

- Common vision and mission. Do the company and its competitors share a common view of the world's evolution? To what extent does competitors' strategic intent match the company's one?

Table 1 The competitive empathy catalyst tool

Common vision and mission

Do the company and its competitors share a common view of the world's evolution? To what extent does the competitors' strategic intent match the company's one?

Symmetric value mechanisms Are the company's and its competitors' value creation, delivery and capture mechanisms to some extent similar and symmetric?

Relatable culture

Do the company and its competitors share a pattern of basic assumptions that help them frame, interpret and respond to internal and external reality in a similar way?
Shared purpose

\section{Orientation}

Is there a common "reason why" the company and its competitors may share, to the benefit of itself and the whole ecosystem?

\section{Execution}

Synergies

What are the touchpoints between the company's and its competitors' business model - in terms of activities, processes, resources and assets - that could generate positive effects for both parties if collectively leveraged?

\section{Foundation}

Similar values and beliefs

Do the company and its competitors have similar standards to tell what is "right" or "wrong," "better" or "worse?"
Non-conflicting strategic goals

Are there any goals the competitors set that would not necessarily lead to conflicting outcomes? If the company were in its place, what objectives would it set? Would any of these objectives lead to common interests?

Complementarities

What are the dual elements between the company's and its competitors' business model that could increase the value created, delivered and captured if collectively bundled?

Resembling corporate identity Do the company and its competitors use visible and tangible representations of their organization (such as logos, products, visual materials and communications) that make them perceived similarly by customers and other stakeholders? 
- Shared purpose. Is there a common purpose the company and its competitors share, to the benefit of itself and the whole ecosystem?

- Non-conflicting strategic goals. Are there any goals the competitors set that would not necessarily lead to conflicting outcomes? If the company were in its place, what objectives would it set? Would any of these objectives lead to common interests?

The Execution layer looks at the competitive positioning and business model through which the company and its competitors' strategy is executed, in terms of the value creation, delivery and capture mechanisms the company puts in place (Cortimiglia et al., 2016). This layer stresses symmetries, synergies and complementarities rather than competitive differentials:

- Symmetric value mechanisms. Are the company's and its competitors' value creation, delivery and capture mechanisms to some extent similar and symmetric?

- Synergies. What are the touchpoints between the company's and its competitors' business model - in terms of activities, processes, resources and assets - that could generate positive results for both parties if collectively leveraged?

- Complementarities. What are the dual elements between the company's and its competitors' business model that could increase the value created, delivered and captured if collectively bundled?

The Foundation layer reflects on the common organizational context the company and its competitors share, in terms of culture, values and beliefs and corporate identity:

- Relatable culture. Do the company and its competitors share a pattern of basic assumptions that help them frame, interpret and respond to internal and external reality in a similar way?

- Similar values and beliefs. Do the company and its competitors have similar standards to tell what is "right" or "wrong," "better" or "worse?"

- Resembling corporate identity. Do the company and its competitors use visible and tangible representations of their organization (such as logos, products, visual materials and communications) that make them perceived similarly by customers and other stakeholders?

Interpreting strategy as competition is management's comfort zone, as managers relying on "cognitive ease" (Kahneman, 2013) automatically associate the notion of the other with that of the enemy. The enemy should be countered through a display of power. However, competitive empathy, supported by the tool of the Competitive Empathy Catalyst, helps to work around this automatic reflex, activate "cognitive strain" (Kahneman, 2013) and realize that empathy is not a weakness but instead a source of countless opportunities.

\section{Competitive empathy principles}

Looking beyond the tool managers should use to identify touchpoints with the competition, competitive empathy works best when managers' strategic behavior and action are inspired by a set of principles:

- Search for a non-conflicting identification with competitors and avoid "egotism." In "The art of war," Sun Tzu wrote that to ensure victory is to know your enemy and yourself, but there is rather little empathy in that lesson. Managers should not simply put themselves in their competitor's shoes for their own advantage and to obtain personal gain but should rather suspend a conflictual stance to truly identify themselves with the other.

- Adopt "perspective-taking." As managers openly assume their competitor's perspective, they should purposefully look for similarities to establish a common ground for a strategic conversation. 
- Practice "mirroring." As mirror neurons neurologically trigger empathy in human beings and animals, managers should try not only to see what their competitors see but also imagine feeling what their competitors feel by matching their emotional state.

- Aim at the "greater good." Rather than concentrating on shorter-term, individual gains and firm advantage, placing managers' interest in long-term welfare and ecosystem advantage may help stimulate empathy.

- Leverage "vicarious learning." Managers should ask themselves whether there is something they can learn from their competitors by observing behavior that they can adapt.

- Apply "cautionary trust." Managers should not give second chances, at least in the short term. Empathy is something that takes time to build and it can be damaged quickly. If the competitor breaks an empathic agreement, the violator should not be forgiven right away. Being empathic does not mean being naïve. Instead, managers should simply say they will not be working with the competitor for a while. This is what consistently happens in entrepreneurial communities where trust is a cohesive force. When it is broken, the breaker is out of the circle of trust and temporarily excluded from key networks and deals, which may be re-entered only after proving to have set a different course of action.

The competitive empathy catalyst offers managers a hands-on tool to focus attention on the strategic aspects that really matter when assessing the chance to establish an empathic relationship with competitors. In turn, competitive empathy principles allow deriving heuristics and guidelines on how to manage the lifecycle of an empathic relationship with competitors, from its engagement:

- Search for a non-conflicting identification with competitors and avoid egotism.

- Adopt perspective-taking.

- Practice mirroring.

- Aim for the greater good.

- Leverage vicarious learning and monitoring.

- Apply cautionary trust.

\section{Competitive empathy in practice: cases and recommendations}

Competitive empathy is the cognitive and emotional enabler for different kinds of interactions with competitors, ranging from simple recognition of common interests for lobbying purposes to coopetition dynamics, long-lasting partnerships and alliances and collective transformation of industries and markets. Seeing things from the competitors' eyes and perspectives is probably the first way to exit a zero-sum game.

For instance, the recent marketing campaign by Burger King calling on customers to order from McDonald's started from a competitively empathic realization that the crisis driven by the world's pandemic was harming the whole food chain market. Recovery could only come from a collective, rather than an egotistic, stance and action based on commonalities that would lead the main players to set a non-conflictual goal such as jointly promoting home delivery, take away or drive-thru services.

$A V I O$, a leading space propulsion company in the European space industry and a founding partner of the Space Economy Observatory I direct, challenged itself to renew its strategy. With its mission to bring space closer, it put itself in competitors' and third parties' shoes to figure out how to cut fixed costs of space missions, which represents the highest entry barrier to space access. As a result, together with several competitors, including 
ArianeSpace within the European Space Agency framework, it co-developed the Small Spacecraft Mission Service, a dispenser that can transport multiple light satellites at once into orbit through a single launch of its Vega rocket. On September 3rd, 2020, the 16th Vega launch set a record by putting into orbit 53 light satellites for 21 public and private clients from 13 different countries, opening an era of what we called "rocket sharing." By recognizing the immense value of sharing a common vision, purpose and objectives and by leveraging symmetries, synergies and complementarities with competitors' business models, AVIO helped the industry shift from competition on space access to the creation of a shared platform for access.

Competitive empathy does not only benefit large companies but also supports the launch and early-stage development of startups.

When launching Orapesce, a digital platform startup I cofounded in 2018 which connects fishermen, end customers and other third parties to deliver clean fish straight to the customer's door, we initially considered local fishing co-ops as our direct competitors. However, competitive empathy and the use of the Catalyst helped us realizing that those players share a similar strategic foundation, execution and orientation with us and our business models displayed both synergies and complementarities.

Concerning the orientation layer, Orapesce and the local fishing co-ops shared a vision based on the need to make the fishing industry healthier and more sustainable, while the mission was to act accordingly by monitoring the whole sea-to-table process. A fairly similar purpose also emerged, which underscored the need to support local fishing communities and provide customers with a more authentic experience. Translating the similar orientation that emerged from the analysis into common goals was not difficult, resulting in the identification of objectives that required, for example, fishing only in the Adriatic sea and avoiding bycatches at all costs. In the execution layer, the startup and its potential competitors' business models showed significant complementarities in the value creation and delivery activities and processed covered, which led them to outsource a large share of the fishing operations to the co-ops. They retained core activities such as platform design and management, marketing and customer care. Ultimately, in terms of foundations, the analysis of competitors and the subsequent dialogues and interactions revealed several similarities in how Orapesce wished to establish its organizational culture and how local fishing co-ops interpreted the world around them. Values and beliefs such as sustainability, transparency, accountability, integrity, honesty, trust, passion and commitment to clients, were shared. Some visible and tangible representations of the corporate identity such as logos and advertising content (e.g. videos, fliers, social media content, web pages) also to some extent resembled one another.

As a result of the application of the catalyst, we decided that rather than competing with fishing co-ops, we could partner by asking them to join our platform as suppliers. This strategic action led Orapesce to become the number one Italian startup in online freshly caught fish delivery during the pandemic.

When I served as a strategic advisor for GEL proximity, a startup founded in 2019 as a university spinoff from Polihub (Politecnico di Milano's Innovation Park and Startup Accelerator) offering logistics and last-mile delivery services, competitive empathy helped to pivot the initial business model. We understood how, rather than competing with the over 45,000 pickup points where customers could choose to collect or return their packages closer to their homes such as post offices, agencies, bars, gas stations, kiosks and smart lockers, which already existed in Italy and were organized in scattered networks, our startup could operate as a meta-platform aggregating these alternative networks in a single virtual place. This could benefit both customer experience and single network owners. Owners could reduce cart abandonment, cut delivery costs by increasing delivery success rate and cut technology costs by introducing a single integration with just one orchestrator managing 
connections with all pickup points. As a result, GEL proximity created the first proximity delivery network in Italy and is currently adding an increasing number of proximity players to the meta-platform.

Practicing competitive empathy does not necessarily lead to a positive outcome of partnerships or coopetition dynamics. What may happen is that, regardless of the effort put into finding similarities and symmetries, the touchpoints may not be significant enough to establish a common ground that benefits both parties. Lock-in and lock-out effects may exist that constrain the ability to form new company-competitor ties. In other cases, even after an empathic connection is established and synergies are found, the competitor may reject the collaboration upfront due to a traditional competitive attrition stance in its management team. Or it may initiate a discussion on possible collaboration only to move away from it shortly afterward and without notice. Such events may trigger a "learning race" dynamic, typical of strategic network interactions, where the competitor's private interests motivate it to engage in a race to learn or exploit as much as it can from its rival's assets and then exit the alliance (Gulati et al., 2000).

However, even when empathic efforts fail, managers may obtain a maverick view on competition that discloses unconventional details and will be beneficial to their company's strategy. Moreover, the very attempt to embrace and practice competitive empathy represents a way to train management's emotional intelligence, which proves a useful skill for the company's key people.

Drawing on the extensive experience gathered, evidenced by the cases we explored, this research finds that practicing competitive empathy gives managers and entrepreneurs an empathic advantage that uplifts them and positively impacts their performance in our connected world.

\section{References}

Bartlett, C.A. and Ghoshal, S. (1994), "Changing the role of top management: beyond strategy to purpose", Harvard Business Review, Vol. 72 No. 6, pp. 79-88.

Bregman, P. (2020), "Empathy starts with curiosity", Harvard Business Review, April 27th, 2020.

Buzzell, R.D., Gale, B.T. and Gale, B.T. (1987), The PIMS Principles: Linking Strategy to Performance, Simon and Schuster.

Cortimiglia, M.N., Ghezzi, A. and Frank, A.G. (2016), "Business model innovation and strategy making nexus: evidence from a cross-industry mixed-methods study", R\&D Management, Vol. 46 No. 3, pp. 414-432.

Duarte, N. (2020), "Five ways to motivate your team with empathy and authority", MIT Sloan Management Review, Column, May 21, 2020, available at: https://sloanreview.mit.edu/article/five-ways-to-motivateyour-team-with-empathy-and-authority/

Frank, A.G., Mendes, G.H., Ayala, N.F. and Ghezzi, A. (2019), "Servitization and industry 4.0 convergence in the digital transformation of product firms: a business model innovation perspective", Technological Forecasting and Social Change, Vol. 141, pp. 341-351.

Ghezzi, A. (2020), "How entrepreneurs make sense of lean startup approaches: business models as cognitive lenses to generate fast and frugal heuristics", Technological Forecasting and Social Change, Vol. 161, p. 120324

Goleman, D., McKee, A. and Waytz, A. (2017), "Empathy”, HBR Emotional Intelligence Series, Harvard Business Press.

Gulati, R., Nohria, N. and Zaheer, A. (2000), "Strategic networks", Strategic Management Journal, Vol. 21 No. 3, pp. 203-215.

Hart, S.L. and Sharma, S. (2004), "Engaging fringe stakeholders for competitive imagination", Academy of Management Perspectives, Vol. 18 No. 1, pp. 7-18.

Kahneman, D. (2013), “Thinking Fast and Slow”, Farras, Straus and Giroux, New York, NY.

\author{
Keywords: \\ Strategy, \\ Competitive advantage, \\ Sustainability, \\ Business model innovation, \\ Business model, \\ Digital transformation, \\ Microfoundations, \\ Purpose, \\ Lean startup, \\ Competitive empathy
}


Malnight, T.W., Buche, I. and Dhanaraj, C. (2019), "Put purpose at the core of your strategy", Harvard Business Review, Vol. 97 No. 5, pp. 70-78.

Myashiro, M.R. and Colonna, J. (2011), The Empathy Factor: Your Competitive Advantage for Personal, Team, and Business Success, Puddle Dancer Press, Encinitas, CA.

Patnaik, D. (2009), Wired to Care. How Companies Prosper When They Create Widespread Empathy, Pearson Education Inc., San Mateo, CA.

Porter, M.E. and Kramer, M.R. (2019), "Creating shared value", Managing Sustainable Business, Springer, Dordrecht, pp. 323-346.

Zaki, J. (2019), "Making empathy Central to your company culture", Harvard Business Review, May 30th, 2019.

\section{Further reading}

Buzzell, R.D., Gale, B.T. and Gale, B.T. (1987), The PIMS Principles: Linking Strategy to Performance, Simon and Schuster.

Tzu, S. (2006), The Art of War, Filiquarian Publishing LLC, New York, NY.

\section{About the author}

Antonio Ghezzi, PhD is an Associate Professor of Strategic Management and Entrepreneurship and Head of the Hi-tech Startups and Space Economy applied research centers at the Department of Management, Economics and Industrial Engineering Politecnico di Milano. His main research interests are business model innovation, Digital Transformation and the role of Lean Startup Approaches for experimentation. He is the author of more than 150 scientific journal articles (appearing in outlets such as Technological Forecasting and Social Change, International Journal of Management Reviews, Journal of Business Research, International Journal of Production Economics, Management Decision and R\&D Management), books, book chapters and conference proceedings. Antonio Ghezzi can be contacted at: antonio1.ghezzi@polimi.it

For instructions on how to order reprints of this article, please visit our website: www.emeraldgrouppublishing.com/licensing/reprints.htm

Or contact us for further details: permissions@emeraldinsight.com 